\title{
Assessing eating disordered behaviour in overweight children and adolescents: bridging the gap between a self-report questionnaire and a gold standard interview
}

Citation for published version (APA):

Jansen, E. L. G. M., Mulkens, S., Hamers, H., \& Jansen, A. T. M. (2007). Assessing eating disordered behaviour in overweight children and adolescents: bridging the gap between a self-report questionnaire and a gold standard interview. Netherlands Journal of Psychology, 63(3), 93-97.

https://doi.org/10.1007/BF03061070

Document status and date:

Published: 01/01/2007

DOI:

10.1007/BF03061070

Document Version:

Publisher's PDF, also known as Version of record

Document license:

Taverne

Please check the document version of this publication:

- A submitted manuscript is the version of the article upon submission and before peer-review. There can be important differences between the submitted version and the official published version of record.

People interested in the research are advised to contact the author for the final version of the publication, or visit the DOI to the publisher's website.

- The final author version and the galley proof are versions of the publication after peer review.

- The final published version features the final layout of the paper including the volume, issue and page numbers.

Link to publication

\footnotetext{
General rights rights.

- You may freely distribute the URL identifying the publication in the public portal. please follow below link for the End User Agreement:

www.umlib.nl/taverne-license

Take down policy

If you believe that this document breaches copyright please contact us at:

repository@maastrichtuniversity.nl

providing details and we will investigate your claim.
}

Copyright and moral rights for the publications made accessible in the public portal are retained by the authors and/or other copyright owners and it is a condition of accessing publications that users recognise and abide by the legal requirements associated with these

- Users may download and print one copy of any publication from the public portal for the purpose of private study or research.

- You may not further distribute the material or use it for any profit-making activity or commercial gain

If the publication is distributed under the terms of Article 25fa of the Dutch Copyright Act, indicated by the "Taverne" license above,

Download date: 26 Apr. 2023 


\title{
Assessing eating disordered behaviour in overweight children and adolescents: bridging the gap between a self-report questionnaire and a gold standard interview
}

\author{
Esther Jansen • Sandra Mulkens • Harm Hamers • \\ Anita Jansen
}

Keywords Assessment · binge eating - childhood . obesity $\cdot$ ChEDE $\cdot$ ChEDE-Q

The current study compared two measurements assessing eating disorder psychopathology in overweight children and adolescents: an interview and a self-report questionnaire. An adjusted version of the Child Eating Disorder Examination Questionnaire (ChEDE-Q) was compared with the Child Eating Disorder Examination interview (ChEDE), which is considered the gold standard. Thirtyeight overweight children and adolescents (aged 8-14) participated in the study. Regarding objective bulimic episodes, the current study found that using smaller chunks of information decreased the discrepancy between interview and questionnaire. The chances are that the gap between ChEDE-Q and ChEDE can be reduced if more attention is paid to children's abilities concerning the understanding of complex concepts. (Netherlands Journal of Psychology, 63, 102-106)

Overweight and obesity are becoming the most significant public health issues of the 21 st century. In the Netherlands, $46 \%$ of all adults are overweight, of which $11 \%$ are obese. At the same time, overweight and obesity are increasingly prevalent in children and adolescents. Currently, one out of eight Dutch children are overweight or obese (CBS, 2005; Visscher, Kromhout \& Seidell, 2002). Because of severe physical and

Esther Jansen, and, $(\varangle)$

Department of Clinical Psychological Science, Faculty of Psychology, Maastricht UniversityCorrespondence to: Esther Jansen, Department of Clinical Psychological Science, Faculty of Psychology, Maastricht University, PO Box 616, NL 6200

MD Maastricht. E-mail: e.jansen@psychology.unimaas.

nlSubmitted 15 March 2006; revision accepted 13 June 2007. psychological health consequences, treatment is necessary. However, prior to treatment, it is important to assess potentially disordered eating behaviours such as binge eating and purging, as the occurrence of these behaviours complicates treatment (Elfhag \& Rossner, 2005).

Among the adult overweight population, binge eating seems a common behaviour. Research suggests that 20 up to $46 \%$ of all treatment-seeking obese adults report eating binges (Bruce \& Wilfley, 1996; de Zwaan \& Mitchell, 1992). In addition, binge eating episodes are reported by 20 to $30 \%$ of obese children (Decaluwé, Braet \& Fairburn, 2003). An eating binge is defined as eating an amount of food that is larger than most people would eat during a short period of time, during which loss of control is experienced (APA, 1994). Binge eating is an ambiguous concept and therefore hard to diagnose (Fairburn \& Wilson, 1993; Jansen, van den Hout \& Griez, 1990).

At present, various instruments are used to diagnose eating disorders and binge eating. The Eating Disorder Examination (EDE; Fairburn \& Cooper, 1993) is considered the gold standard for assessing specific eating psychopathology. As the EDE should be administered by a trained interviewer (Cooper \& Fairburn, 1987), this method is far more time-consuming and more expensive than, for example, a self-report questionnaire (Black \& Wilson, 1996). Another disadvantage might be that a semi-structured interview such as the EDE allows less anonymity, which might lead to a lower degree of honesty, especially when it comes to delicate issues (Carter, Aimé \& Mills, 2001).

The Eating Disorder Examination Questionnaire (EDE-Q; Fairburn \& Beglin, 1994) was developed as a possible substitute for the EDE. A study by Luce and Crowther (1999) suggests that the subscales of the EDE- 
Q have high levels of internal consistency (Cronbach's a ranged from 0.78 to 0.93 ). However, the EDE-Q proved to have difficulties in identifying more complex conceptual issues, such as binge eating (Black \& Wilson, 1996; Fairburn \& Beglin, 1994).

The same problems arise when the children's versions of these instruments are compared. In a study by Decaluwé and Braet (2004), the child version of the EDE (ChEDE; Bryant-Waugh et al, 1996) and the child version of the EDE-Q (ChEDE-Q; Decaluwé, 1999) were compared. It was found that the four subscales of the ChEDE correlated significantly with the corresponding subscales of the ChEDE-Q ( $r$ ranging from 0.42 to 0.76 ). However, scores on the ChEDE-Q subscales were found to be consistently higher than scores on the ChEDE subscales. When comparing the ChEDE and the ChEDE-Q in assessing objective bulimic episodes the researchers did not find any significant correlation between the two instruments. The ChEDE-Q produced significantly higher scores with respect to binge eating. The discrepancy between the ChEDE and ChEDE-Q thus concerns binge eating behaviour in particular. The probable cause of these results lies in the fact that it is very difficult to identify bulimic episodes and the concepts involved.

Because of the major advantage of saving expenses and time when using questionnaires, improving the ChEDE-Q seems to be of great value. With respect to a complex conceptual issue like binge eating, the consistency between the two instruments might well be improved by explaining ambiguous concepts in the questionnaire.

Passi, Bryson \& Lock (2003) examined whether adding information for adults led to a smaller discrepancy between EDE and EDE-Q. This research showed that adults studied the extra information and used it when filling in the questionnaire. Yet, because of the small number of participants $(n=28)$, no firm conclusions could be drawn.

In the current study we attempt to further reduce the gap between the EDE interview and questionnaire for children by appending information explaining ambiguous concepts such as 'binge eating', 'loss of control' and 'large amounts of food'. It is hypothesised that the addition of this information results in a smaller discrepancy between the two instruments in children, especially with respect to objective bulimic episodes.

If it proves possible to increase the agreement between the two instruments, the ChEDE-Q might be welcomed as a useful alternative for the time-consuming and costly ChEDE.

\section{Method}

Subjects

Thirty-eight children and adolescents (30 girls and 8 boys) participated in the current study. The mean age of the participants was 11.3 years $(S D=1.43$, range $8-14$ years) with a mean BMI percentile of $94.49(S D=5.81$, range 75.2 -99.6).

All children had been participating in a free outpatient treatment programme for overweight, provided by Maastricht University. The current research was integrated in one of the follow-up measurements. Informed consent was obtained from the children's parents. After completing the measurements, the children were allowed to choose a small present.

Measurements

\section{Child Eating Disorder Examination}

The ChEDE (Bryant-Waugh, Cooper, Taylor \& Lask, 1996) is a version of the adult EDE adapted for children (Fairburn \& Cooper, 1993). It consists of four subscales; restraint, eating concern, shape concern and weight concern. Furthermore, the ChEDE measures overeating (objective bulimic episodes, subjective bulimic episodes and objective overeating episodes) and methods of weight control (self-induced vomiting, laxative misuse, diuretic misuse and intense exercising). The ChEDE consists of 35 items that are scored on a seven-point (0-6) rating scale. Higher scores indicate greater seriousness or frequency of the given feature.

\section{Child Eating Disorder Examination Questionnaire}

The Child Eating Disorder Examination Questionnaire (ChEDE-Q; Decaluwé, 1999) is based on the Eating Disorder Examination Questionnaire (EDE-Q; Fairburn \& Beglin, 1994) for adults. It is a self-report questionnaire measuring the existence and frequency of eating disorder psychopathology. The EDE-Q consists of 30 items, each corresponding to an item of the original EDE. The ChEDE-Q also consists of 30 items, using a seven-point rating scale.

For the current study, some adjustments were made to the ChEDE-Q. The adjusted questionnaire did not make use of seven response possibilities, but of 28: each of the 28 boxes represented one of the past 28 days the questionnaire asks about. This was done to visually enhance children's notion of the past 28 days. The children had to 
colour the number of boxes (that is, days) on which they had experienced the feature asked about. Afterwards, the investigator transcribed these scores into the original seven-point rating scores. Furthermore, another important change was the insertion of definitions of the ambiguous concepts used in the ChEDE-Q: 'loss of control', 'eating binge', 'eating in secret', 'large amount of food' and 'intense exercising'.

In the present study the Cronbach alpha coefficients for each subscale were 0.53 for 'restraint', 0.65 for 'eating concern', 0.57 for 'weight concern' and 0.83 for 'shape concern' respectively. These are comparable with alphas found in other studies (Decaluwé \& Braet, 2004).

\section{Procedure}

The interview and questionnaire were both administered during the same follow-up measurement and therefore related to the same preceding 28-day period. As Decaluwé and Braet (2004) recommended, a 28-day diary was used to enhance recall during the administration of both the questionnaire and the interview. The adapted version of the ChEDE-Q was administered at the beginning of the measurement. Subsequently, the child completed a number of other questionnaires which were irrelevant for this study. Then, the ChEDE was administered. Finally, the child was measured and weighed. The order in which the ChEDE-Q and ChEDE were administered was not counterbalanced. As previous studies (Black \& Wilson, 1996; Decaluwé \& Braet, 2004; Fairburn \& Beglin, 1994) have argued, administering the interview first could elucidate key concepts and consequently influence scores on the adjusted ChEDE-Q.

\section{Results}

Data reduction and analysis

To establish the degree of correspondence between the ChEDE and ChEDE-Q, first the subscale scores of both measures were calculated. Correlations and t-tests were computed to compare the subscale scores, the global score as well as overeating and compensatory behaviour. The level of agreement was also calculated for all these variables. Agreement is met when the ChEDE-Q score lies within a one-scale point range of the ChEDE score. With respect to the ChEDE-Q, an eating binge can be diagnosed in two ways. Item 8 comprises both the concepts of eating a large amount of food and the loss of control in a single question ('Have you had episodes of binge eating?'), whereas items 16 and 17 address these two concepts separately (item 16 focuses on eating a large amount of food whereas item 17 enquires about loss of control).

Consequently, an eating binge can be diagnosed by an affirmative response to item 8 or by affirmative responses to both items 16 and 17. Regarding the results of the present study we examined both ways of diagnosing eating binges.

\section{Subscales}

Table 1 shows the scores of both the interview and the questionnaire. The four subscales of the ChEDE and ChEDE-Q were all significantly correlated, with correlations ranging from 0.40 to 0.78 . Comparisons of the subscales show that scores on the interview and the questionnaire are significantly different with respect to 'eating concern' and 'shape concern'; questionnaire scores are significantly higher than interview scores. Regarding the other two subscales, 'restraint' and 'weight concern', there were no significant differences between interview and questionnaire. The level of agreement is rather high for all four subscales, ranging from 73 to $92 \%$ agreement within one scale-point.

Objective bulimic episodes

Table 1 shows the binge eating scores of the interview and questionnaire. Because the ChEDE did not determine

Table 1 Comparison of the ChEDE and ChEDE-Q $(n=38)$.

\begin{tabular}{|c|c|c|c|c|c|c|}
\hline & ChEDEM (SD) & ChEDE-QM (SD) & $\begin{array}{r}\mathrm{M}(\mathrm{SD}) \text { of } \\
\text { difference between } \\
\text { ChEDE-Q and ChEDE }\end{array}$ & $\mathrm{R}$ & $\mathrm{t}$ & $\begin{array}{r}\% \text { Agreement } \\
\text { within 1-scale } \\
\text { point }\end{array}$ \\
\hline Restraint & $1.18(0.97)$ & $1.20(0.85)$ & $0.016(1.00)$ & $0.40^{*}$ & -0.10 & 77.9 \\
\hline Eating concern & $0.25(0.26)$ & $0.47(0.55)$ & $0.324(0.46)$ & $0.55^{* *}$ & $-4.29 * *$ & 92.1 \\
\hline Weight concern & $1.53(0.99)$ & $1.62(1.05)$ & $0.137(0.68)$ & $0.78 * *$ & -1.19 & 73.4 \\
\hline Shape concern & $0.73(0.79)$ & $1.29(1.05)$ & $0.557(0.69)$ & $0.75 * *$ & $-4.90 * *$ & 76.7 \\
\hline Objective bulimic episodes ${ }^{1}$ & $0.0(0.00)$ & $1.03(2.37)$ & & & & 76.3 \\
\hline Objective bulimic episodes ${ }^{2}$ & $0.00(0.00)$ & $0.26(0.89)$ & & & & 94.7 \\
\hline
\end{tabular}


any binge eating episodes in all 38 participants, no correlation with ChEDE-Q scores could be calculated nor could a t-test be performed. However, it is noteworthy that the results indicate an evident difference between the two scoring methods of the ChEDE-Q. When binge eating is assessed by ChEDE-Q items 16 and 17 instead of item 8, the scores resemble the ChEDE scores to a higher degree, resulting in less false-positives.

\section{Discussion}

The aim of the current study was to improve the ChEDEQ (Decaluwé, 1999) by providing clarification of complex concepts used in questions and modifying the response possibilities. To determine whether these alterations were actually improvements, the ChEDE-Q scores were compared with the ChEDE scores in 38 overweight or obese children.

Earlier research findings have shown that there is a substantial discrepancy between the interview and questionnaire: scores on all four subscales differ significantly between the two measures. In addition, the most salient difference between the two measurements is found with respect to the assessment of objective bulimic episodes: the questionnaire proves to overestimate the number of eating binges in comparison with the interview (Decaluwé \& Braet, 2004).

By adapting the ChEDE-Q in the current study through exemplifying certain concepts, inserting definitions and adapting the response format, this discrepancy decreased. When the questionnaire and the interview were compared, the four subscales were all significantly correlated. The correlations obtained are comparable with those found by Decaluwé and Braet (2004). In other words, in general, scores on the questionnaire appeared higher than scores on the interview. With regard to the subscales 'eating concern' and 'shape concern', these differences were significant. However, the discrepancy found in the current study is not as considerable as the discrepancy found by Decaluwé and Braet (2004), who found that all four subscales differed significantly between interview and questionnaire. With respect to objective bulimic episodes, it was shown that the discrepancy between interview and questionnaire was reduced from 1.03 to 0.26 points when an eating binge was scored based on affirmative responses on both item 16 (eating large amounts of food) and 17 (loss of control) instead of solely on item 8 (episodes of binge eating). Agreement between the two measures was $76.3 \%$ based on item 8 and $94.7 \%$ based on the combination of items 16 and 17.
These results indicate that the adjustments made are indeed improvements to the ChEDE-Q, in that the scores resemble those of the ChEDE more closely. Concerning the future use of self-report questionnaires measuring eating disordered behaviour (in children, but possibly also in adults), it would be recommended to further examine the effects of clarifying vague concepts, questioning these concepts in manageable and meaningful chunks (for example splitting binge eating into loss of control and eating large amounts of food) and modifying response possibilities.

Obviously, this study shows some limitations. First, the results are based on a fairly small sample $(n=38)$. Therefore, these findings need to be replicated in a larger sample. Secondly, being an allied problem, the diagnosis of bulimic episodes was not made according to the gold standard in any of the participating overweight or obese children.

A larger sample size could probably solve this problem as well. A third limitation, which is connected to the previous one, might be that the study was carried out with children who had already completed treatment. It would be better to carry out this research before participants start treatment. Yet, the question is whether this really causes problems for interpreting the results as within-group differences implicate an improvement when questions are subdivided into smaller chunks.

In conclusion, the current study found that adjustments to the ChEDE-Q reduce the gap between interview and self-report questionnaire. Adding up that self-report questionnaires are less time consuming, do not require a trained interviewer, cost less, possibly result in more sincere answers to delicate issues and do not bring about an instrumentation effect, it seems worthwhile to consider investing time and money in further improving and refining the ChEDE-Q.

\section{Author's note}

Main fields of interest: childhood obesity, treatment, parental control, eating behaviour in children.

\section{References}

American Psychiatric Association (1994). Diagnostic and Statistical Manual of Mental disorders, $4^{\text {th }}$ edition. Washington, DC: American Psychiatric Association.

Black, C.M.D., \& Wilson, G.T. (1996). Assessment of eating disorders: interview versus questionnaire. International Journal of Eating Disorders, 20, 43-50.

Bruce, B., \& Wilfley, D. (1996). Binge eating among the overweight population: a serious and prevalent problem. Journal of the American Dietetic Association, 96, 58-61. 
Bryant-Waugh, R.J., Cooper, P.J., Taylor, C.L., \& Lask, B. D. (1996). The use of the Eating Disorder Examination with children: a pilot study. International Journal of Eating Disorders, 19, 391-397.

Carter, J.C., Aimé, A.A., \& Mills, J.S. (2001). Assessment of bulimia nervosa: a comparison of interview and self-report questionnaire methods. International Journal of Eating Disorders, 30, 187-192.

Centraal Bureau voor de Statistiek (2005). Gerapporteerde gezondheid en leefstijl, percentages / aantallen, totaal kenmerk gebruikers. Statline CBS: http://statline.cbs.nl/statweb

Cooper, Z., \& Fairburn, C.G. (1987). The Eating Disorder Examination: a semi structured interview for the assessment of the specific psychopathology of eating disorders. International Journal of Eating Disorders, 6, 1-8.

De Zwaan, M., \& Mitchell, J.E. (1992). Binge eating in the obese. Annals of Medicine, 24, 303-308.

Decaluwé, V. (1999). Child Eating Disorder Examination-Questionnaire. Dutch translation and adaptation of the Eating Disorder Examination-Questionnaire, authored by C.G. Fairburn \& S.J. Beglin. Unpublished manuscript.

Decaluwé, V., Braet, C., \& Fairburn, C. G. (2003). Binge eating in obese children and adolescents. International Journal of Eating Disorders, 33, 78-84.

Decaluwé, V., \& Braet, C. (2004). Assessment of eating disorder psychopathology in obese children and adolescents: interview versus self-report questionnaire. Behaviour Research and Therapy, 42, 799-811.
Elfhag, K., \& Rossner, S. (2005). Who succeeds in maintaining weight loss? A conceptual review of factors associated with weight loss maintenance and weight regain. Obesity Reviews, 6, 67-85.

Fairburn, C.G., \& Cooper, Z. (1993). The Eating Disorder Examination (12th edition). In: C.G. Fairburn \& G.T. Wilson (Eds.), Binge eating: nature, assessment and treatment (pp. 317-360). New York: Guilford Press.

Fairburn, C.G., \& Wilson, G.T. (1993). Binge eating: definition and classification. In: C.G. Fairburn \& G.T. Wilson (Eds.), Binge eating: nature, assessment and treatment (pp. 3-15). New York: Guilford Press.

Fairburn, C.G., \& Beglin, S.J. (1994). Assessment of eating disorders: interview or self-report questionnaire? International Journal of Eating Disorders, 16, 363-370.

Jansen, A., van den Hout, M., \& Griez, E. (1990). Clinical and nonclinical binges. Behaviour Research and Therapy, 28, 439-444.

Luce, K.H., \& Crowther, J.H. (1999). The reliability of the Eating Disorder Examination-Self-Report Questionnaire Version (EDE-Q). International Journal of Eating Disorders, 25, 349351.

Passi, V.A., Bryson, S.W., \& Lock, J. (2003). Assessment of eating disorders in adolescents with anorexia nervosa: self-report questionnaire versus interview. International Journal of Eating Disorders, 33, 45-54.

Visscher, T.L., Kromhout, D., \& Seidell, J.C. (2002). Long term and recent time trends in the prevalence of obesity among Dutch men and women. International Journal of Obesity, 26, 1218-1224. 